\title{
Genotypic and phenotypic characterization of Mycobacterium tuberculosis resistance against fluoroquinolones in the northeast of Iran
}

Mahdieh Sayadi ${ }^{1,2+}$, Hosna Zare ${ }^{1,2,3 \dagger}$, Saeed Amel Jamedar ${ }^{1,2}$, Seyed Isaac Hashemy ${ }^{4}$, Zahra Meshkat ${ }^{1,2}$, Saman Soleimanpour ${ }^{1,2}$, Sven Hoffner ${ }^{5}$ and Kiarash Ghazvini ${ }^{1,2^{*}}$ (i)

\begin{abstract}
Background: Fluoroquinolones are broad-spectrum antibiotics that are recommended, and increasingly important, for the treatment of multidrug-resistant tuberculosis (MDR-TB). Resistance to fluoroquinolones is caused by mutations in the Quinolone Resistance Determining Region (QRDR) of gyrA and gyrB genes of Mycobacterium tuberculosis. In this study, we characterized the phenotypic and genotypic resistance to fluoroquinolones for the first time in northeast Iran.

Methods: A total of 123 Mycobacterium tuberculosis isolates, including 111 clinical and 12 collected multidrugresistant isolates were studied. Also, 19 WHO quality control strains were included in the study. The phenotypic susceptibility was determined by the proportion method on Löwenstein-Jensen medium. The molecular cause of resistance to the fluoroquinolone drugs ofloxacin and levofloxacin was investigated by sequencing of the QRDR region of the gyrA and gyrB genes.

Results: Among 123 isolates, six (4.8\%) were fluoroquinolone-resistant according to phenotypic methods, and genotypically three of them had a mutation at codon 94 of the gyrA gene (Asp $\rightarrow$ Gly) which was earlier reported to cause resistance. All three remaining phenotypically resistant isolates had a nucleotide change in codon 95. No mutations were found in the gyrB gene. Five of the $19 \mathrm{WHO}$ quality control strains, were phenotypically fluoroquinolone-resistant, four of them were genotypically resistant with mutations at codon 90, 91 of the gyrA gene and one resistant strain had no detected mutation.

Conclusions: Mutation at codon 94 of the gyrA gene, was the main cause of fluoroquinolone resistance among $M$. tuberculosis isolates in our region. In 3/6 fluoroquinolone-resistant isolates, no mutations were found in either gyrA or gyrB. Therefore, it can be concluded that various other factors may lead to fluoroquinolone resistance, such as active efflux pumps, decreased cell wall permeability, and drug inactivation.
\end{abstract}

Keywords: Mycobacterium tuberculosis, MDR-TB, Resistance, XDR-TB, Fluoroquinolone

\footnotetext{
*Correspondence: Ghazvinik@mums.ac.ir; kiarash_ghazvini@yahoo.com

${ }^{\dagger}$ Mahdieh Sayadi and Hosna Zare contributed equally to this work.

'Antimicrobial Resistance Research Center, Mashhad University of Medical Sciences, Mashhad, Iran

${ }^{2}$ Department of Microbiology and Virology, Faculty of Medicine, Mashhad University of Medical Sciences, Mashhad, Iran

Full list of author information is available at the end of the article
}

(c) The Author(s). 2020 Open Access This article is licensed under a Creative Commons Attribution 4.0 International License, which permits use, sharing, adaptation, distribution and reproduction in any medium or format, as long as you give appropriate credit to the original author(s) and the source, provide a link to the Creative Commons licence, and indicate if changes were made. The images or other third party material in this article are included in the article's Creative Commons licence, unless indicated otherwise in a credit line to the material. If material is not included in the article's Creative Commons licence and your intended use is not permitted by statutory regulation or exceeds the permitted use, you will need to obtain permission directly from the copyright holder. To view a copy of this licence, visit http://creativecommons.org/licenses/by/4.0/ The Creative Commons Public Domain Dedication waiver (http://creativecommons.org/publicdomain/zero/1.0/) applies to the data made available in this article, unless otherwise stated in a credit line to the data. 


\section{Background}

Tuberculosis (TB) is among the leading health problems, especially in low-income countries, and is considered as the first cause of death from an infectious disease and ninth cause of death worldwide [1-5]. The emergence of multidrug-resistant (MDR) form of this disease makes the treatment difficult even in developed countries [6]. Inappropriate use of antibiotics has led to the development of MDR-TB and extensively drug-resistant tuberculosis (XDR-TB). MDR-TB is defined as Mycobacterium tuberculosis strains that are resistant to the main first-line drugs (isoniazid and rifampin) [7]. XDR-TB strains are characterized by resistance to at least one of the three injectable aminoglycosides (kanamycin, amikacin, capreomycin) and fluoroquinolones (FQs), as well as isoniazid and rifampin [8]. The development of such resistant strains is a serious threat to the global control of tuberculosis [9-11].

FQs are synthetic chemotherapeutic agents that have broad antibacterial effects on mycobacteria [12]. Regarding the excellent pharmacokinetic and pharmacodynamic properties, FQs are considered as the most effective second-line drug and among the recommended therapy for MDR-TB [12-19]. Since FQs have broadspectrum activity, they are usually overprescribed for various other bacterial infections, and they are easily accessible as over-the-counter medications in many resource-limited countries, exacerbating their misuse $[18,20]$. This has led to the increased emergence of FQresistant $M$. tuberculosis strains [21, 22]. Resistance can also be developed due to the incomplete adherence to the TB treatment program, failure in previous treatment and contact with patients of resistant tuberculosis [18].

The FQ resistance is due to mutations of the quinolone resistance determining region (QRDR) in the gyr $A$ and gyrB genes of $M$. tuberculosis [23], most common by mutation in codon 90,91 , and 94 of the gyrA gene. In a minority of cases, FQ resistance has been shown to be associated with mutations in the gyrB gene [24].

According to WHO reports in 2017, the global proportion of MDR-TB/rifampin-resistant TB (RR-TB) with resistance to any of the FQs ofloxacin, levofloxacin, and moxifloxacin was $20 \%[23,25,26]$. Drug resistance of $M$. tuberculosis is an essential obstacle for effective treatment and control of TB. Therefore, timely detection of drug-resistant TB (DR-TB), including FQs, is necessary to reduce the transmission and to initiate effective drug therapy without any delay [27].

In this study, the resistance of $M$. tuberculosis against ofloxacin and levofloxacin was investigated by phenotypic and genotypic diagnostic methods for the first time in Northeastern Iran. This region has high importance regarding the TB prevalence due to migration from neighboring countries [28]. We selected a drug from the second-line anti-TB treatment (ofloxacin) and also a drug from the third-line (levofloxacin) and used the recommended test concentration of $2 \mu \mathrm{g} / \mathrm{ml}$. The phenotypic susceptibility was determined by the proportion method on Lowenstein-Jensen medium. Genotypic susceptibility was evaluated by investigating possible resistance-related mutations by Sanger sequencing of the QRDR of gyrA and gyrB genes.

\section{Methods \\ Sample collection}

A total of 111 clinical isolates, including 109 pulmonary and two extra-pulmonary specimens, were collected from patients that referred to the Tuberculosis Regional Reference Laboratory in Mashhad. We included all confirmed TB patients referred to the hospital for 1 year (March 2017-February 2018). Confirmation was based on AFB smear tests, culture on LJ medium, chest $\mathrm{x}$-ray, and clinical presentations. Also, 12 MDR-TB isolates related to the referred TB patients were obtained from the Mycobacterium Bank of the Department of Microbiology at Mashhad University of Medical Sciences during April 2014-February 2017. It should be noted that none of our 111 collected clinical isolates were MDR. Furthermore, 19 WHO quality control strains sent to the Tuberculosis Regional Reference Laboratory of Mashhad were included in this study. From the 111 collected clinical isolates (from 64 men, 47 women), we had 85 patients with primary tuberculosis (52 men, 33 women), 15 patients with relapse (five men, 10 women), eight patients under treatment (five men, three women) and three patients with treatment failure (two men, one woman). There were 103 Iranian patients and eight from neighboring countries. The $12 \mathrm{MDR}-\mathrm{TB}$ isolates (from 10 men and two women) included nine Iranian, two Afghan, and one Kazakh patient.

Specimens were digested and decontaminated by Petroff's method, and the smear stained with Ziehl-Neelsen method. The specimens were also cultured on a Lowenstein-Jensen culture medium. Positive specimens were identified and confirmed by IS6110 PCR.

\section{Antimicrobial agents}

Based on previous studies on the MIC of FQs in Iran and other countries, two concentrations of two antibiotics were selected. We used both concentrations of 2 and $4 \mu \mathrm{g} / \mathrm{ml}$ for ofloxacin and levofloxacin. As results were the same for both concentrations, the breakpoint for ofloxacin and levofloxacin (Temad, Iran) was selected as $2 \mu \mathrm{g} / \mathrm{ml}$ according to the WHO recommendations and our results [27]. To prepare this concentration, 20 $\mathrm{mg}$ of each antibiotic was dissolved in $10 \mathrm{ml}$ of $0.1 \mathrm{~N}$ $\mathrm{HCl}$, and $1 \mathrm{ml}$ of the suspension was added to $9 \mathrm{ml}$ of distilled water. Then, $1 \mathrm{ml}$ of the above solution was 
filtered $(0.22 \mu \mathrm{m})$ and added to $99 \mathrm{ml}$ of autoclaved Lowenstein-Jensen culture medium after cooling (Merck, Heidelberg, Germany).

\section{Drug susceptibility test (DST)}

Drug susceptibility test was performed by the proportion method on Lowenstein-Jensen medium. A microbial suspension containing $3 * 10^{8} \mathrm{CFU} / \mathrm{ml}$ was prepared $(1$ McFarland) and diluted to 1:100, 1:10000 and 1:100000. Then, $0.2 \mathrm{ml}$ of these were added to the LowensteinJensen medium and incubated at $37^{\circ} \mathrm{C}$ for 28 days. The H37Rv reference strain was used as the control in the drug susceptibility test. All the strains in this study were also tested for the first-line TB drugs including isoniazid, rifampin, and ethambutol.

\section{DNA extraction}

According to the simple boiling protocol for DNA extraction, $400 \mu \mathrm{l}$ of deionized distilled water or $0.5 \% \mathrm{TE}$ buffer was added into a $1.5 \mathrm{ml}$ microtube, and a colony was also put in the tube. Then, it was centrifuged at $13000 \mathrm{~g}$ for $30 \mathrm{~min}$ and the supernatant was removed gently. After that, we performed two steps of washing with TE buffer $(10 \mathrm{mM}$ Tris- $\mathrm{HCl}, 1 \mathrm{mM}$ EDTA, $\mathrm{pH}=8)$ and centrifuged at $13000 \mathrm{~g}$. The appropriate amount of TE buffer was added to the pellet $(200-400 \mu \mathrm{l})$ and boiled for $30 \mathrm{~min}$. Then, 13,000 g centrifugation was performed, and the supernatant containing DNA was used for molecular tests.

The sequence of $g y r A$ and $g y r B$ primers and the product size are shown in Table 1 . The $100 \mu \mathrm{M}$ stock solution of lyophilized primers (Microsynth, Switzerland) was prepared according to manufacturer instructions. The non-diluted primer was stored at $-70^{\circ} \mathrm{C}$ and the diluted primer at $-20^{\circ} \mathrm{C}$.

\section{Polymerase chain reaction}

For gyrA gene amplification, a total volume of $40 \mu \mathrm{l}$ containing $4 \mu \mathrm{l}$ of the $10 \mathrm{X}$ PCR buffer, $2 \mu \mathrm{l} \mathrm{MgCl}_{2}, 1 \mu \mathrm{l}$ dNTPs, $0.4 \mu \mathrm{l}$ PFU enzyme, $1 \mu \mathrm{l}$ Dimethyl sulfoxide (DMSO), $5 \mu \mathrm{l}$ of the DNA template, $2 \mu \mathrm{l}$ of each of the primers and $22.6 \mu \mathrm{l}$ of the deionized distilled water (DDW) was prepared. The thermal conditions were as follows: 1 cycle of $95^{\circ} \mathrm{C}$ for $5 \mathrm{~min}$, followed by 40 cycles of $95^{\circ} \mathrm{C}$ for $35 \mathrm{~s}, 61^{\circ} \mathrm{C}$ for $30 \mathrm{~s}$, and $72^{\circ} \mathrm{C}$ for $45 \mathrm{~s}$, and 1 cycle of $72^{\circ} \mathrm{C}$ for $5 \mathrm{~min}$.
To amplify the gyrB gene, a total volume of $40 \mu \mathrm{l}$ containing $4 \mu \mathrm{l}$ of the $10 \mathrm{X}$ PCR buffer, $2 \mu \mathrm{l} \mathrm{MgCl}, 1 \mu \mathrm{l}$ dNTPs, $0.4 \mu \mathrm{l}$ PFU enzyme, $1 \mu \mathrm{l}$ DMSO, $5 \mu \mathrm{l}$ of the DNA template, $2 \mu \mathrm{l}$ of each of the primers and $22.6 \mu \mathrm{l}$ of the DDW was prepared. The cycling conditions in thermal cycler were as follows: 1 cycle of $95^{\circ} \mathrm{C}$ for $5 \mathrm{~min}$, followed by 40 cycles of $95^{\circ} \mathrm{C}$ for $35 \mathrm{~s}, 54^{\circ} \mathrm{C}$ for $30 \mathrm{~s}$, and $72{ }^{\circ} \mathrm{C}$ for $50 \mathrm{~s}$, and 1 cycle of $72^{\circ} \mathrm{C}$ for $10 \mathrm{~min}$. To confirm the gene amplification, electrophoresis on 1.5\% agarose gel was performed in the voltage of $90 \mathrm{~V}$ and time of 40-50 min.

\section{Sequencing}

For sequencing by the Sanger method, $25 \mu \mathrm{l}$ of PCR product was sent to Microsynth, Switzerland. Results of sequencing were analyzed by Chromas V 1.45, DNAMAN V 4.13, MEGA V 5.05 and Blast software at NCBI site.

\section{Results}

Phenotypic drug susceptibility

In this study, to measure the susceptibility against ofloxacin and levofloxacin, the proportion method was used. Six isolates (4.8\%, five men and one woman) of the 123 tested samples from Iran and five isolates of the 19 WHO control strains, showed resistance to $2 \mu \mathrm{g} / \mathrm{ml}$ ofloxacin and levofloxacin. The results of antibiotic susceptibility tests of isolates are shown in Table 2. We had three FQ mono-resistant isolates (3/111) which mean being resistant only to FQs, but sensitive to all first-line TB drugs. These three isolates were all related to Iranian patients. Two of them were new TB cases and one was a TB relapse which was treated before with a 6-month rifampicin-based regimen $2 \mathrm{HRZE} / 4 \mathrm{HR}$ according to the WHO treatment protocol [31].

\section{Genotyping}

The PCR reaction for gyr $A$ and gyrB genes was performed on all $11 \mathrm{FQ}$-resistant isolates (3/111 clinical isolates, 3/12 MDR isolates, and 5/19 WHO control strains) and the $M$. tuberculosis $\mathrm{H} 37 \mathrm{Rv}$ reference strain. Genotyping was done by Sanger sequencing the QRDR region of the $g y r A$ and $g y r B$ genes.

No mutations were found in the gyrA and gyrB genes of the drug-susceptible $\mathrm{H} 37 \mathrm{Rv}$ strain. From the three phenotypically FQ-resistant isolates among 111 clinical

Table 1 Nucleotide sequence of primers and the amplicon size

\begin{tabular}{|c|c|c|c|c|c|}
\hline Target organism & Gene & Primer sequence & Amplicon size & $T_{m}$ & Reference \\
\hline \multirow[t]{4}{*}{ M. tuberculosis } & gyrA & F: CAGCGCAGCTACATCGACTA & $356 \mathrm{bp}$ & 61 & {$[27]$} \\
\hline & & R: CTCAGCATCTCCATCGCCAA & & & \\
\hline & gyrB & F: GCAACACCGAGGTCAAATC & $710 \mathrm{bp}$ & 57 & [29] \\
\hline & & R: ACCCTTGTACCGCTGAATG & & & \\
\hline
\end{tabular}


Table 2 Classification of isolates of Tuberculosis Regional Reference Laboratory in Mashhad ( $n=123$ ) based on antibiotic susceptibility testing and distribution of gyrA and gyrB genes mutation patterns

\begin{tabular}{|c|c|c|c|c|c|c|}
\hline \multirow[t]{2}{*}{ Gene } & \multirow[t]{2}{*}{ Nucleotide change } & \multirow[t]{2}{*}{ Amino acid change } & \multicolumn{2}{|c|}{ Clinical isolates $(n=111)$} & \multirow{2}{*}{$\begin{array}{l}\text { MDR-TB } \\
(n=12)\end{array}$} & \multirow{2}{*}{$\begin{array}{l}\text { Polydrug } \\
\text { resistant } \\
(n=0)\end{array}$} \\
\hline & & & $\begin{array}{l}\text { Pansusceptible } \\
(\boldsymbol{n}=108)\end{array}$ & $\begin{array}{l}\text { FQ mono-resistant } \\
(\boldsymbol{n}=3)^{\mathbf{a}}\end{array}$ & & \\
\hline \multirow[t]{3}{*}{ gyrA } & $C(269) \rightarrow T$ & Ala $(90) \rightarrow$ Val & - & - & - & - \\
\hline & $\mathrm{T}(271) \rightarrow C$ & Ser $(91) \rightarrow$ Pro & - & - & - & - \\
\hline & $A(281) \rightarrow G$ & Asp(94) $\rightarrow$ Gly & - & 1 (new case) & $2(X D R)^{b}$ & - \\
\hline gyrB & - & - & - & - & - & - \\
\hline \multicolumn{3}{|c|}{ Phenotypically FQ resistant, without any gyrase mutations } & - & 2 (1 new, 1 relapse) & 1 & - \\
\hline \multicolumn{3}{|c|}{ All phenotypically FQ resistant } & - & 3 & $3^{c}$ & - \\
\hline
\end{tabular}

Note: Pansusceptible: susceptible to all first-line anti-TB drugs, FQ mono resistance: being resistant only to FQ, but sensitive to all first-line TB drugs, MDR-TB: resistance to at least both isoniazid and rifampin, Polydrug resistance: resistance to more than one first-line anti-TB drug, other than both isoniazid and rifampin ${ }^{a}$ These three isolates were all related to Iranian patients. Two of them were new TB cases and one was a TB relapse

${ }^{b}$ These two MDR isolates were resistant to FQs and also they were found to be resistant against kanamycin and amikacin in another study by our colleagues on these isolates [30]. Both were TB treatment failure cases, one from Afghanistan and one from Kazakhstan

${ }^{\mathrm{c}}$ All were treatment failure cases

isolates, one carried mutation at codon $94(\mathrm{Asp} \rightarrow \mathrm{Gly})$ which was an Iranian new TB case and two others had no gyrase mutation (one Iranian new $\mathrm{TB}$ case and one Iranian TB relapse explained before). From the three phenotypically FQ-resistant isolates among 12 MDR isolates, two of them carried mutation at codon 94 (both were TB treatment failure cases, one from Afghanistan and one from Kazakhstan) and one had no gyrase mutation (an Iranian TB treatment failure case). The G284C polymorphism encoding S95T polymorphism was detected in $100 \%$ of isolates. The frequency of nucleotide substitutions among different groups is provided in Table 2.

\section{Results of WHO quality control strains}

From the five phenotypically FQ-resistant strains among 19 WHO strains, four were also genotypically resistant. Two cases had mutation at codon $90(\mathrm{Ala} \rightarrow \mathrm{Val})$, and two had simultaneous mutations in codons 90 (Ala $\rightarrow-$ Val) and 91 (Ser $\rightarrow$ Pro). The one remaining strain of phenotypically FQ-resistant WHO strains had no gyrase mutations. Data of WHO control strains are mentioned only to validate the phenotyping and genotyping results, and they are not related to Iranian samples. All the findings about control strains were in agreement with the WHO consensus results.

\section{Discussion}

MDR-TB and XDR-TB are significant barriers to TB control programs, especially in low and middle-income countries. The risk of XDR-TB increases due to the inappropriate use of second-line anti-TB drugs, and the treatment of XDR-TB is challenging, time-demanding, costly, and often related to a poor treatment outcome [32]. The results of a meta-analysis for the treatment response of 6724 MDR-TB patients showed a 64\% treatment success, while $48 \%$ for FQ-resistant cases.
Therefore, routine screening is required to detect FQ resistance [33].

In this study, a second-line anti-TB drug (ofloxacin) and a third-line drug (levofloxacin) were evaluated for the analysis of phenotypic DST and genotypic resistance to FQs. They were examined on 111 clinical isolates of M. tuberculosis, 12 MDR-TB isolates, and also $19 \mathrm{WHO}$ quality control strains sent to the laboratory.

The critical concentration was $2 \mu \mathrm{g} / \mathrm{ml}$ according to the WHO recommendation [27]. In the total 123 isolates of northeastern Iran, six isolates showed concurrent resistance against both these FQs. Three of these resistant isolates were among the 111 clinical isolates which were fully susceptible to the first-line anti-TB drugs isoniazid, rifampin, and ethambutol. This shows that FQ monoresistance is a problem in Iran that risks the efficient treatment of MDR-TB due to the overuse of this drug for the treatment of community-acquired pneumonia and other bacterial diseases, as well as the treatment of non-TB respiratory symptoms $[21,22]$.

The fact that three (25\%) out of 12 MDR-TB isolates were FQ-resistant, clearly shows that the incidence of XDR-TB or pre-XDR-TB in the northeast of Iran is worrisome. Timely drug susceptibility tests should be implemented to manage MDR-TB. It should be noted that two XDR samples were identified in this study among 12 MDR isolates as they were FQ-resistant and also have shown resistance against kanamycin and amikacin in another study by our colleagues on these isolates [30]. Both of the XDR-TB isolates were treatment failure cases and related to foreign nationals (Afghanistan, Kazakhstan), which indicates the effect of migration on tuberculosis epidemiology as the east border countries of Iran is a source of infection and affect the $\mathrm{TB}$, and especially drug-resistant TB prevalence in Iran [28].

Rapid molecular methods facilitate the diagnosis of MDR-TB and pre-XDR-TB isolates in smear-positive 
samples and they should be used as the primary method to obtain early drug susceptibility results. The most commonly used molecular methods for the detection of FQ resistance include PCR, DNA sequencing, and lineprobe assays.

In this study on 123 isolates, six FQ-resistant isolates were identified by the phenotypic method, while three were detected by sequencing. We observed the mutations only for gyrA and not for gyrB which is in accordance with the study by Arjomandzadegan et al. in Iran and Belarus [34], suggesting that the resistance of $M$. tuberculosis to FQs is generally caused by mutations in the gyrA gene [23]. Yu et al. in China reported only one (1.6\%) mutated gyrB from 60 levofloxacin-resistant $M$. tuberculosis clinical isolates [35]. gyrA sequencing had a sensitivity of $50 \%$ to detect clinically relevant FQ resistance in our study. The sensitivity of the sequencing method for FQ resistance was reported as $77.5 \%$ by Chen et al. and $87.8 \%$ by Moure et al. [27, 36].

In this study, all our three genotypically resistant samples carried a mutation at codon 94, while the genotypically resistant WHO strains had mutations at codons 90 and 91. In a study by Arjomandzadegan et al. in Iran, 24/42 (57\%) FQ-resistant strains of M. tuberculosis carried mutations at codon 94 [34]. In a report by Singh et al. in Tokyo, $g y r A$ and $g y r B$ mutations were reported in 79 and 5\% among 100 ofloxacin-resistant isolates [37]. In a study by Singhal et al., 25/152 isolates had mutations in the gyrA gene with the most common mutations at the codon 94 , while no mutations were reported in the $\operatorname{gyr} B$ gene [38].

We found 2.7\% (3/111) FQ-resistant strains that were sensitive to all first-line drugs. Sharma et al. in India reported that the occurrence of FQ mono-resistant strains sensitive to the first-line treatment was 3.2\% (35/1099) [39]. Kim et al. in Korea found 0.7\% (38/5221) FQ mono-resistance [40]. The existence of FQ monoresistant $\mathrm{TB}$ cases would be a warning against the widespread use of this drug.

There were 3/6 (50\%) FQ-resistant isolates that did not harbor any gyrA or gyrB mutations. In a similar study by Zhang et al. in China, more than $30 \%$ of FQresistant strains had no mutations in the QRDRs of $g y r A$ and $\operatorname{gyr} B$ [41]. It is believed that FQ-resistant strains with no gyrase mutations probably represent heteroresistance, which is the simultaneous presence of drugsusceptible and drug-resistant bacilli. The frequency of heteroresistance has been reported in 14 to $38 \%$ of FQresistant $M$. tuberculosis isolates [42].

This study was the first describing FQ-resistant TB in northeast Iran. We used two FQs from the two lines of TB treatment and performed both phenotypic and genotypic diagnostic methods which have not been done before in our region.

\section{Conclusions}

In conclusion, a relationship between phenotypic resistance to FQs and mutations in QRDRs was detected among M. tuberculosis clinical isolates of Iran. In our study, mutation at codon 94 of the gyrA gene was the main cause of resistance to FQs in M. tuberculosis isolates. Three of the six FQ-resistant isolates showed a mutation in the gyrA gene, which causes resistance and the remaining three isolates had nucleotide change in the codon 95, which is not related to resistance. It suggests that different factors lead to the resistance of $M$. tuberculosis to FQs, such as mutations outside the QRDR of the gyrA gene or reduced cell wall permeability and efflux pump mechanisms [43]. Due to the inappropriate use of FQs, the resistance to these drugs in the northeast of Iran can be a warning and should be monitored. In our study, gyrA sequencing had a sensitivity of $50 \%$ for clinical resistance.

\section{Abbreviations \\ TB: Tuberculosis; FQ: Fluoroquinolone; MDR: Multi-Drug Resistant; XDR- TB: Extensively Drug-Resistant Tuberculosis; QRDR: Quinolone Resistance Determining Region; RR-TB: Rifampin Resistant TB; DST: Drug Susceptibility Test; DMSO: Dimethyl Sulfoxide; DDW: Deionized Distilled Water}

\section{Acknowledgements}

Not applicable.

\section{Authors' contributions}

MS, KG, SH conceived and designed the study and contributed in specimen collection. HZ, SAJ, SIH, ZM, SS contributed to the study protocol and analyzed and interpreted the data. MS, HZ, KG, SH drafted the manuscript, critically reviewed it and prepared the final version. All authors read and approved the final manuscript.

\section{Funding}

This study was financially supported by the Deputy of Research, Mashhad University of Medical Sciences (950691).

\section{Availability of data and materials}

All data generated or analysed during this study are included in this article.

\section{Ethics approval and consent to participate}

The ethical approval for performing this study was obtained from the Ethics Committee of the Mashhad University of Medical Sciences and written informed consent was obtained from participants.

\section{Consent for publication}

Not applicable.

\section{Competing interests}

The authors declare that they have no competing interests.

\section{Author details}

${ }^{1}$ Antimicrobial Resistance Research Center, Mashhad University of Medical Sciences, Mashhad, Iran. ${ }^{2}$ Department of Microbiology and Virology, Faculty of Medicine, Mashhad University of Medical Sciences, Mashhad, Iran.

${ }^{3}$ Student Research Committee, Mashhad University of Medical Sciences, Mashhad, Iran. ${ }^{4}$ Department of Clinical Biochemistry, Faculty of Medicine, Mashhad University of Medical Sciences, Mashhad, Iran. ${ }^{5}$ Department of Global Public Health, Karolinska Institute, Stockholm, Sweden. 
Received: 11 May 2019 Accepted: 20 May 2020

Published online: 01 June 2020

\section{References}

1. WHO. Global tuberculosis report. Geneva: World Health Organization; 2016 Report No.: 924156539X

2. Neshani A, Kakhki RK, Sankian M, Zare H, Chichaklu AH, Sayyadi M, et al. Modified genome comparison method: a new approach for identification of specific targets in molecular diagnostic tests using Mycobacterium tuberculosis complex as an example. BMC Infect Dis. 2018;18(1):517.

3. Kakhki RK, Neshani A, Sankian M, Ghazvini K, Hooshyar A, Sayadi M. The short-chain dehydrogenases/reductases (SDR) gene: a new specific target for rapid detection of Mycobacterium tuberculosis complex by modified comparative genomic analysis. Infect Genet Evol. 2019;70:158-64.

4. Kaniga K, Cirillo DM, Hoffner S, Ismail NA, Kaur D, Lounis N, et al. A multilaboratory, multi-country study to determine bedaquiline minimal inhibitory concentration quality control ranges for phenotypic drug-susceptibility testing. J Clin Microbiol. 2016;JCM:01123-16.

5. Mehrabadi SM, Taraghian M, Pirouzi A, Khaledi A, Neshani A, Rashki S. Pulmonary Nocardiosis in suspected tuberculosis patients: a systematic review and meta-analysis of cross-sectional studies. Ethiop J Health Sci. 2020;30(2):293-300.

6. Shi W, Forsman LD, Hu Y, Zheng $X$, Gao Y, Li X, et al. Improved treatment outcome of multidrug-resistant tuberculosis with the use of a rapid molecular test to detect drug resistance in China. Int J Infect Dis. 2020; S1201-9712(20):30265-4.

7. Dalton T, Cegielski P, Akksilp S, Asencios L, Caoili JC, Cho S-N, et al. Prevalence of and risk factors for resistance to second-line drugs in people with multidrug-resistant tuberculosis in eight countries: a prospective cohort study. Lancet. 2012;380(9851):1406-17.

8. WHO. WHO Global Task Force outlines measures to combat XDR-TB worldwide. Geneva: WHO; 2006

9. Ruan Q, Liu Q, Sun F, Shao L, Jin J, Yu S, et al. Moxifloxacin and gatifloxacin for initial therapy of tuberculosis: a meta-analysis of randomized clinical trials. Emerg Microbes Infect. 2016;5(2):e12

10. Izadi N, Samiei A, Ghazvini K. Co-infection of long-standing extensively drug-resistant Mycobacterium tuberculosis (XDR-TB) and non-tuberculosis mycobacteria: a case report. Respir Med Case Rep. 2015;15:12-3.

11. Zignol M, Dean AS, Alikhanova N, Andres S, Cabibbe AM, Cirillo DM, et al. Population-based resistance of Mycobacterium tuberculosis isolates to pyrazinamide and fluoroquinolones: results from a multicountry surveillance project. Lancet Infect Dis. 2016;16(10):1185-92.

12. Tagliani E, Cabibbe AM, Miotto P, Borroni E, Toro JC, Mansjö M, et al. Diagnostic performance of the new version (v2. 0) of GenoType MTBDRsl assay for detection of resistance to fluoroquinolones and second-line injectable drugs: a multicenter study. J Clin Microbiol. 2015; 53(9):2961-9.

13. Principi N, Esposito S. Appropriate use of fluoroquinolones in children. Int J Antimicrob Agents. 2015;45(4):341-6.

14. Bacci C, Galli L, de Martino M, Chiappini E. Fluoroquinolones in children: update of the literature. J Chemother. 2015;27(5):257-65

15. Kamal S, Hossain A, Sultana S, Begum V, Haque N, Ahmed J, et al. Antituberculosis drug resistance in Bangladesh: reflections from the first nationwide survey. Int J Tuberc Lung Dis. 2015;19(2):151-6.

16. Aldred KJ, Blower TR, Kerns RJ, Berger JM, Osheroff N. Fluoroquinolone interactions with Mycobacterium tuberculosis gyrase: enhancing drug activity against wild-type and resistant gyrase. Proc Natl Acad Sci. 2016; 113(7):E839-E46

17. Fox GJ, Oxlade O, Menzies D. Fluoroquinolone therapy for the prevention of multidrug-resistant tuberculosis in contacts. A cost-effectiveness analysis Am J Respir Crit Care Med. 2015;192(2):229-37.

18. Chang KC, Yew WW, Chan RCY. Rapid assays for fluoroquinolone resistance in Mycobacterium tuberculosis: a systematic review and meta-analysis. J Antimicrob Chemother. 2010;65(8):1551-61.

19. Sotgiu G, Migliori GB. Facing multi-drug resistant tuberculosis. Pulm Pharmacol Ther. 2015;32:144-8.

20. Jabeen K, Shakoor S, Chishti S, Ayaz A, Hasan R. Fluoroquinolone-resistant Mycobacterium tuberculosis, Pakistan, 2005-2009. Emerg Infect Dis. 2011;17(3):566.
21. Van Der Heijden Y, Maruri F, Holt E, Mitchel E, Warkentin J, Sterling T. A comparison of interview methods to ascertain fluoroquinolone exposure before tuberculosis diagnosis. Epidemiol Infect. 2015;143(5):960-5.

22. Ignatyeva O, Balabanova Y, Nikolayevskyy V, Koshkarova E, Radiulyte B, Davidaviciene $\mathrm{E}$, et al. Resistance profile and risk factors of drug resistant tuberculosis in the Baltic countries. Tuberculosis. 2015:95(5):581-8.

23. Mayer $\mathrm{C}$, Takiff $\mathrm{H}$. The molecular genetics of fluoroquinolone resistance in Mycobacterium tuberculosis. Molecular Genetics of Mycobacteria, Second Edition: American Society of Microbiology; 2014. p. 455-78.

24. Aubry A, Veziris N, Cambau E, Truffot-Pernot C, Jarlier V, Fisher LM. Novel gyrase mutations in quinolone-resistant and-hypersusceptible clinical isolates of Mycobacterium tuberculosis: functional analysis of mutant enzymes. Antimicrob Agents Chemother. 2006;50(1):104-12.

25. Bernard C, Veziris N, Brossier F, Sougakoff W, Jarlier V, Robert J, et al. Molecular diagnosis of fluoroquinolone resistance in Mycobacterium tuberculosis. Antimicrob Agents Chemother. 2015;59(3):1519-24.

26. Bernard C, Aubry A, Chauffour A, Brossier F, Robert J, Veziris N. In vivo Mycobacterium tuberculosis fluoroquinolone resistance emergence: a complex phenomenon poorly detected by current diagnostic tests. J Antimicrob Chemother. 2016;71(12):3465-72.

27. Chen J, Peng P, Du Y, Ren Y, Chen L, Rao Y, et al. Early detection of multidrug-and pre-extensively drug-resistant tuberculosis from smearpositive sputum by direct sequencing. BMC Infect Dis. 2017;17(1):300.

28. Tavakoli A. Incidence and prevalence of tuberculosis in Iran and neighboring countries. Zahedan J Res Med Sci. 2017;19(7):e9238.

29. Bakuła Z, Napiórkowska A, Kamiński M, Augustynowicz-Kopeć E, Zwolska Z, Bielecki J, et al. Second-line anti-tuberculosis drug resistance and its genetic determinants in multidrug-resistant Mycobacterium tuberculosis clinical isolates. J Microbiol Immunol Infect. 2016:49(3):439-44.

30. Askarizadeh F, Aryan E, Hashemy SI, Youssefi M, Farsiani H, Ghazvini K. Prevalence and molecular characterization of Mycobacterium tuberculosis resistance to aminoglycosides in the Northeast of Iran. Acta microbiologica Hellenica. 2019;64(3):59-66.

31. Organization WH. Guidelines for treatment of drug-susceptible tuberculosis and patient care. 2017

32. Jain N, Agnihotri S. Extensively drug resistance (XDR) TB-is not always fatal; 2009.

33. Falzon D, Gandhi N, Migliori GB, Sotgiu G, Cox HS, Holtz TH, et al. Resistance to fluoroquinolones and second-line injectable drugs: impact on multidrugresistant TB outcomes. Eur Respir J. 2013;42(1):156-68.

34. Arjomandzadegan M, Titov L, Farnia P, Owlia P, Ranjbar R, Sheikholeslami F, et al. Molecular detection of fluoroquinolone resistance-associated gyrA mutations in ofloxacin-resistant clinical isolates of Mycobacterium tuberculosis from Iran and Belarus. Int J Mycobacteriol. 2016;5(3):299-305.

35. Yin X, Yu Z. Mutation characterization of gyrA and gyrB genes in levofloxacin-resistant Mycobacterium tuberculosis clinical isolates from Guangdong Province in China. J Infect. 2010;61(2):150-4.

36. Moure R, Tudó G, Medina R, Vicente E, Caldito JM, Codina MG, et al. Detection of streptomycin and quinolone resistance in Mycobacterium tuberculosis by a low-density DNA array. Tuberculosis. 2013:93(5):508-14

37. Singh $P$, Jain A, Dixit $P$, Prakash $S$, Jaiswal I, Venkatesh $V$, et al. Prevalence of gyr $A$ and $B$ gene mutations in fluoroquinolone-resistant and-sensitive clinical isolates of Mycobacterium tuberculosis and their relationship with MIC of ofloxacin. J Antibiotics. 2015;68(1):63.

38. Singhal R, Reynolds PR, Marola JL, Epperson LE, Arora J, Sarin R, et al. Sequence analysis of fluoroquinolone resistance-associated genes gyrA and gyrB in clinical Mycobacterium tuberculosis isolates from patients suspected of having multidrug-resistant tuberculosis in New Delhi, India. J Clin Microbiol. 2016;54(9):2298-305.

39. Sharma $R$, Singh BK, Kumar $P$, Ramachandran $R$, Jorwal $P$. Presence of Fluoroquinolone mono-resistance among drug-sensitive Mycobacterium tuberculosis isolates: an alarming trend and implications. Clin Epidemiol Global Health. 2019;7(3):363-6.

40. Kim H, Mok JH, Kang B, Lee T, Lee H-K, Jang HJ, et al. Trend of multidrug and fluoroquinolone resistance in Mycobacterium tuberculosis isolates from 2010 to 2014 in Korea: a multicenter study. Korean J Intern Med. 2019;34(2):344.

41. Zhang Z, Lu J, Wang Y, Pang Y, Zhao Y. Prevalence and molecular characterization of fluoroquinolone-resistant Mycobacterium tuberculosis isolates in China. Antimicrob Agents Chemother. 2014:58(1):364-9. 
42. Rigouts L, Miotto P, Schats M, Lempens P, Cabibbe A, Galbiati S, et al.

Fluoroquinolone heteroresistance in Mycobacterium tuberculosis: detection by genotypic and phenotypic assays in experimentally mixed populations. Sci Rep. 2019;9(1):1-8.

43. Pasca MR, Guglierame P, Arcesi F, Bellinzoni M, De Rossi E, Riccardi G. Rv2686c-Rv2687c-Rv2688c, an ABC fluoroquinolone efflux pump in

Mycobacterium tuberculosis. Antimicrob Agents Chemother. 2004;48(8): 3175-8.

\section{Publisher's Note}

Springer Nature remains neutral with regard to jurisdictional claims in published maps and institutional affiliations.

Ready to submit your research? Choose BMC and benefit from:

- fast, convenient online submission

- thorough peer review by experienced researchers in your field

- rapid publication on acceptance

- support for research data, including large and complex data types

- gold Open Access which fosters wider collaboration and increased citations

- maximum visibility for your research: over $100 \mathrm{M}$ website views per year

At BMC, research is always in progress.

Learn more biomedcentral.com/submissions 